\title{
Halliwick Concept of Swimming and its Influence on Motoric Competencies of Children with Severe Disabilities
}

\author{
Tereza Vaščáková, Martin Kudláček \\ Palacky University, Olomouc, Czech Republic \\ Ursula Barrett \\ Institute of Technology, Tralee, Ireland
}

\begin{abstract}
The purpose of this study was to describe the influence of Halliwick concept of swimming on development of motor competencies of children with cerebral palsy and autism. Participants of this study were ten children with severe disabilities - cerebral palsy (CP) and autism (mean age 5.5 years). Aquatic skills were evaluated using Water orientation test (WOTA) created by Tirosh, KatzLeurer and Getz (2008). Gross motor skills were evaluated using Gross motor function measure (GMFM) by Russell, Rosenbaum, Avery, \&Lane (2002). Testing was done at the beginning and at the end of ten week Halliwick swimming intervention. Verbal evaluation was recorded after every swimming lesson. Results of WOTA testing showed improvement of aquatic skills in children with diparetic cerebral palsy by 0.64 points, in children with quadruparetic cerebral palsy by 0.76 points and in children with autism by 1.18 points. Gross motor skills improved by $4.25 \%$ in children with diparetic CP, $1.57 \%$ in children with autism and $5.20 \%$ in children with quadruparetic CP.
\end{abstract}

Keywords: adapted aquatics, cerebral palsy, autism

The research shows that the early stimulation in water can bring multiple benefits to children with disabilities (Aleksandrovic, Jorgic, Block \& Jovanovic, 2016; Becker, 2004; Stan, 2012). Swimming is one of the most appropriate physical activity for persons with cerebral palsy (CP). However, children with $\mathrm{CP}$ and other neurological disorders require special approaches and teaching methods. One of the most appropriate methods to teach adapted aquatics to persons with $\mathrm{CP}$ is Halliwick concept of adapted aquatics (Getz, Hutzler \& Vermeer, 2006a). Halliwick method is teaching specialized for children with disabilities and at the same time can be successfully used for children with fear of water (Pacholík, Vlčková \& Blahutková, 2009). Success in aquatic environment transfers to better self-esteem, self-efficacy and courage (Šarinová \&Čechovská, 2005). Halliwick concept (HC) is specific form of water based therapy using unique attributes of aquatic environment (e.g. pressure, buoyancy, instability) and following very specific principles (Halliwick AST, 1992). In HC three basic principles are used: (a) individual approach, (b) personal one to one contact, and (c) independency of swimmers. This means that every swimmer is always working one to one with personal instructor, who knows student very much and can adjust teaching according to current situation and readiness of student. The biggest advantage of $\mathrm{HC}$ is that students learn at their own pace and abilities. No specific equipment or floating devices are used during Teaching in $\mathrm{HC}$ as specific equipment (floating devices) usually negatively affect physiological swim movements (Saulová, 2007).Getz, Hutzler and Vermeer (2006a) have done systematic review of 173 articles on adapted aquatics from databases MEDLINE, PubMed, ERIC, PsychLit, PEDro, Sport Discus, CINAHL, Cochrane from 1966 till 2005. Among these articles they presented 11 which are focused on children with $\mathrm{CP}$. Seven articles describe positive impact of adapted aquatics on motor functions of children with $\mathrm{CP}$, two show positive impact on personality development 
and two articles did not show significant improvements in neither area. Getz, Hutzler and Vermeer (2006b) in article „The relationship between aquatic independence and Gross motor function measure (GMFM) in children with neuro-motor impairments"present study of impact of HC on gross motor developments among 49 children with CP. Tirosh, Katz-Leurer and Getz (2008) also studied the effect of $\mathrm{HC}$ on children with $\mathrm{CP}$ and created specific 10-point evaluation tool for the Halliwick concept titled WOTA (The water orientation test of Alyn). The purpose of this study was to analyze the impact of $\mathrm{HC}$ on specific adapted aquatics skills according to WOTA evaluation.

\section{Method}

Ten children with disabilities ( 6 boys and 4 girls) age 5.5 years (SD 1.5 years) with cerebral palsy and combined impairments attending special school were selected to participate in the study. The study took place in the rehabilitation center Elpis with pool sized ( $20 \times 5$ meters and depths 1.2 meters) and water temperature $32.0^{\circ} \mathrm{C} \pm 1.5^{\circ} \mathrm{C}$. Tests of GMFM were done in special room for the individual physiotherapy treatment (temperature $23^{\circ} \mathrm{C}$ ). WOTA tests were measured in the pool where adapted aquatics took the place. All tests were done by principal investigator in this study. Aquatic intervention was done at the same time of the day and included preparation, aquatic lesson and transfer to changing rooms.

\section{Measurements}

The GMFM by Russell et al. (2002) consists of 66 items that have been grouped into five dimensions of gross motor function: (a) lying and rolling, (b) sitting, (c) crawling and kneeling, (d) standing, and (e) walking, running and jumping. Each item is scored on a 3 - point Likert scale. A percentage score is calculated for each dimension. Moreover, overall scores can be calculated, as the mean of the five dimension scores. In the present paper the five dimension scores and the
GMFM total scores have been used. Water orientation test (WOTA) by Tirosh, KatzLeurer and Getz (2008) consists 13 items scored on 4- point Likert scale according to quality of aquatic skills. The highest score that can be reached is 52 points .

\section{Intervention}

Halliwick concept was created by James M. Milan from England and currently is widely used in many European countries (e.g. England, Austria, Slovenia, Poland, Czech Republic). Halliwick concept (HC) is specific form of water based therapy using unique attributes of aquatic environment (e.g. pressure, buoyancy, instability) and following very specific principles (Halliwick AST, 1992). The Halliwick Concept (HC) follows a ten-point program which provides a logical sequence to developing aquatic skills at a pace that suits the individual swimmer. In $\mathrm{HC}$ three basic principles are used: (a) individual approach, (b) personal one to one contact, and (c) independency of swimmers. This means that every swimmer is always working one to one with personal instructor, who knows student very much and can adjust teaching according to current situation and readiness of student. Basic presumption is that instructor continues with teaching new steps only after student acquires previous (less difficult) technique. Generally, there is less anxiosity among students and games are widely used for the teaching. The basic element of Halliwick concept is stability and buoyancy in the water, which in the combination of proper breathing can lead to relaxation and control of movement in the water. Teacher always works with student in face to face contact in one on one later moving to group activities. $\mathrm{HC}$ is very effective in students with $\mathrm{CP}$, amputations or intellectual disabilities and it helps the students to enjoy the aquatic environment. Practical guide to $\mathrm{HC}$ is The Ten Point Program created by James McMillan consists of logical sequence of steps needed to become fully adjusted to aquatic environment in order to learn to swim: 1. Mental Adjustment, 2. Disengagement, 3. Transversal 
Rotation Control (formerly Vertical Rotation), 4. Sagittal Rotation Control, 5. Longitudinal Rotation Control (formerly Lateral Rotation), 6. Combined Rotation Control, 7. Upthrust, 8. Balance in Stillness, 9. Turbulent Gliding, 10. Simple Progression and Basic Swimming Movement (Gresswell et al, 2012).

Results

Students with diparetic form of cerebral palsy ( 2 males, 1 female) improved by $4.25 \%$ on GMFM scores. In subscales there were following improvements (a) lying and rolling $-0.00 \%$, (b) sitting - $3.85 \%$, (c) crawling and kneeling - $2.81 \%$, (d) standing $-4.37 \%$, and (e) walking, running and jumping $-5.97 \%$. In WOTA scores students with diparetic form of cerebral palsy improved on average by 0.64 points and overall improvement by 8.33 . The most significant improvement was in the learning of transfer to/from water. Students overcame barriers associated with the accessibility of swimming pool and learnt new transfers, which can also be used in their activities of daily living (ADL). The improvement was also evident in breathing control as from functional view breathing control is one of the key aspects in swimming. It is hard to change breathing stereotypes and to breathe in by nose and out by mouth. Student were initially many times out of breath and were swallowing water, which led to discomfort in water. Second problematic skill to learn was to submerge. Some students were able to submerge under the water, but orientation under the water was too difficult for them. This is also reason why this activity is divided into two parts: (a) submerging under the water and (b) orientation under the water. Practicing vertical position, followed by independent standing and quadrupedal horizontal locomotion was for the students with limited bipedal locomotion very interesting. These activities are perfect for training of physiological walk. Because of proprioceptive stimulation from soles students are learning about new independent movement with the weight support from water. From this point is very important the improvement in the following skills (See Table 1) - horizontal rotation, vertical rotation, independent stand and quadrupedal locomotion.

Table 1 Results for Students with Diparetic form of Cerebral Palsy

\begin{tabular}{|l|c|c|c|}
\hline Aquatic Skill & Pretest & Postest & Difference \\
\hline General adjustment & 2,67 & 3,33 & 0,67 \\
\hline Entering pool & 2,33 & 2,67 & 0,33 \\
\hline Exiting pool & 2,00 & 2,67 & 0,67 \\
\hline Blowing bubbles in the water & 1,67 & 2,67 & 1,00 \\
\hline Horizontal rotation & 2,00 & 3,00 & 1,00 \\
\hline Back floating & 2,33 & 3,00 & 0,67 \\
\hline Splashing water & 2,33 & 2,67 & 0,33 \\
\hline Submerging/diving & 2,00 & 2,67 & 0,67 \\
\hline Maintaining vertical position & 2,33 & 2,67 & 0,33 \\
\hline Vertical quadrupedal locomotion & 2,00 & 3,00 & 1,00 \\
\hline Standing in water at chest level & 2,33 & 3,00 & 0,67 \\
\hline Holding rope: water at chest level & 2,67 & 2,67 & 0,00 \\
\hline Sitting in water & 2,33 & 3,33 & 1,00 \\
\hline AVERAGE IMPROVEMENT & 2,23 & 2,87 & 0,64 \\
\hline \hline OVERALL IMPROVEMENT & 29,00 & 37,33 & 8,33 \\
\hline
\end{tabular}


Students with qvadruparetic form of cerebral palsy ( 2 males, 1 female) improved by $5.20 \%$ on GMFM scores. In subscales there were following improvements (a) lying and rolling $-5.40 \%$, (b) sitting $-7.20 \%$, (c) crawling and kneeling - $2.70 \%$, (d) standing $3.75 \%$, and (e) walking, running and jumping - $1.75 \%$. In WOTA scores students with qvadruparetic form of cerebral palsy improved on average by 0.74 points and overall improvement by 9.67. This improvement is 1.34 higher from diparetic form of $\mathrm{CP}$. The main reason for this difference is starting WOTA results. Students with diparetic CP started the intervention with overall score 29.00 points while students with quadruparetic
CP only reached 27.00 at the end of intervention. We did not expect significant improvements in swim skills due to severity of disability, but still this group made good improvements in following aquatic skills (Table 2): breath control, gliding and rotations. Rotation related skills can be greatly valued in activities of daily living. We have also seen some improvements in quadrupedal locomotion and vertical stand. It is very important as we cannot practice these skills outside of water due to severity of the disability. Therefore, we have used these newly acquired skills to work on bipedal locomotion, activation of proprioception and grasps in vertical activities.

Table 2 Results for Students with Quadruparetic form of Cerebral Palsy

\begin{tabular}{|l|c|c|c|}
\hline Aquatic Skill & Pretest & Postest & Difference \\
\hline General adjustment & 2,00 & 3,00 & 1,00 \\
\hline Entering pool & 1,00 & 1,67 & 0,67 \\
\hline Exiting pool & 1,00 & 1,67 & 0,67 \\
\hline Blowing bubbles in the water & 1,33 & 2,33 & 1,00 \\
\hline Horizontal rotation & 1,33 & 2,33 & 1,00 \\
\hline Back floating & 1,00 & 1,67 & 0,67 \\
\hline Splashing water & 1,67 & 2,67 & 1,00 \\
\hline Submerging/diving & 1,67 & 1,67 & 0,00 \\
\hline Maintaining vertical position & 1,67 & 2,67 & 1,00 \\
\hline Vertical quadrupedal locomotion & 1,00 & 1,67 & 0,67 \\
\hline Standing in water at chest level & 1,00 & 1,67 & 0,67 \\
\hline Holding rope: water at chest level & 1,67 & 1,67 & 0,00 \\
\hline Sitting in water & 1,00 & 2,33 & 1,33 \\
\hline AVERAGE IMPROVEMENT & 1,33 & 2,08 & 0,74 \\
\hline \hline OVERALL IMPROVEMENT & 17,33 & 27,00 & 9,67 \\
\hline
\end{tabular}

Students with autism (2 males, 2 females) improved by $1.57 \%$ on GMFM scores. In subscales there were following improvements (a) lying and rolling $-0.00 \%$, (b) sitting $-0.00 \%$, (c) crawling and kneeling $-0.00 \%$, (d) standing - $3.50 \%$, and (e) walking, running and jumping $-2.80 \%$. In WOTA scores students with autism showed average improvements by 1.16 points. This group improved most of the three groups on overall scoring with increase by 15.13 points.
It is challenging to teach students with autism new skills and habits in new environment. Therefore, we put lot of emphasis on the first skill - water adaptation. We were successful in water adaptation and pool entry as well as other skills related to adaptation to the environment. We had lowest posttest scores on gliding and activities related with relaxation, breathing, submerging or buoyancy. Quadrupedal and bipedal locomotion in water were not problematic for this group and 
therefore we were able to focus also on independent in the aquatic environment. swimming techniques as students felt safe and

Table 3 Results for Students with Autism

\begin{tabular}{|l|c|c|c|}
\hline Aquatic Skill & Pretest & Postest & Difference \\
\hline General adjustment & 2,25 & 3,50 & 1,25 \\
\hline Entering pool & 1,50 & 2,75 & 1,25 \\
\hline Exiting pool & 1,75 & 2,50 & 0,75 \\
\hline Blowing bubbles in the water & 1,75 & 3,00 & 1,25 \\
\hline Horizontal rotation & 1,63 & 2,50 & 0,88 \\
\hline Back floating & 1,25 & 2,50 & 1,25 \\
\hline Splashing water & 1,50 & 2,50 & 1,00 \\
\hline Submerging/diving & 2,00 & 2,75 & 0,75 \\
\hline Maintaining vertical position & 1,25 & 2,50 & 1,25 \\
\hline Vertical quadrupedal locomotion & 1,50 & 2,50 & 1,00 \\
\hline Standing in water at chest level & 1,50 & 3,00 & 1,50 \\
\hline Holding rope: water at chest level & 1,75 & 3,25 & 1,50 \\
\hline Sitting in water & 1,75 & 3,25 & 1,50 \\
\hline AVERAGE IMPROVEMENT & 1,64 & 2,81 & 1,16 \\
\hline \hline OVERALL IMPROVEMENT & 21,38 & 36,50 & 15,13 \\
\hline
\end{tabular}

\section{Discussion}

We confirmed that the Halliwick Concept of adapted aquatics is an appropriate therapy, which also leads to learning desirable aquatics skills. WOTA is also appropriate evaluation tool for adapted aquatics of students with $\mathrm{CP}$ as well as students with autism. Getz et al. (2006b) did bigger scale study with 40 students (children aging 3-7 years mainly with $\mathrm{CP})$. The have used evaluation tool AIM (Aquatic Independence Measure) which is more detailed then WOTA evaluation used in our study. They have showed $77 \%$ improvement in swimming skills, $70 \%$ improvement in breathing control and 62\% improvement in water submerge. We have showed improvement in water submerge in $40 \%$ of students. Getz et al. (2006b) showed $90 \%$ improvement in water transfers and in our case $70 \%$ of students improved in this skill.
Perspective

We wanted to show that Halliwick Concept brings students the improvements in motor competencies and aquatic skills. If we can provide water of appropriate temperature adapted aquatics can help to reduce spasticity, functional strength, mobility and proprioception improvements, reduction of subjective problems and psychological state. These impacts are yet to be discovered in following studies, but so we can recommend Halliwick Concept as appropriate activity, which can improve quality of lives of persons with cerebral palsy.

Acknowledgement

This study was supported by project IGA_FTK_2015_007"Physical activity and lifestyle as the determinants of health and quality of life of persons withdisabilities" 


\section{References}

Aleksandrovic, M., Jorgic, B., Block, M., \& Jovanovic, L. (2016). The effects of aquatic activities on physical fitness and aquatic skills in children with autism spectrum disorders: A systematic review. Facta Universitatis, Series: Physical Education and Sport, 351-362.

Association of swimming therapy. (1992) Swimming for people with disabilities. London, England: A \& C Black

Becker, B. E. (2004). Biophysiologic aspects of hydrotherapy. In A. J. Cole \& B. E. Becker (Eds.). Comprehensive aquatic therapy.

The research shows that the early stimulation in water can bring multiple benefits to children with disabilities (Aleksandrovic, Jorgic, Block \& Jovanovic, 2016; Becker, 2004; Stan, 2012).

Getz, M., Hutzler, Y., Vermeer, A. (2006a). Effects of aquatic interventions in children with neuromotor impairments: a systematic review of the literature. Clinical Rehabilitation, 20, 927-936.

Getz, M., Hutzler, Y., Vermeer, A. (2006b). The Relationship Between Aquatic Independence and Gross Motor Function in Children with Neuro-Motor Impairments. Adapted physical activity quarterly. 339355.

Grosse, S., J. (2010). Water freedom for all: the Halliwick method, International Journal of Aquatic Research and Education, 4. 199-207.

Harris, R. \& Dendy, E. (1992). Swimming for people with disabilities, London, England: A \& C Black

Pacholík, V. (2010). Ve vodě s úsměvem. (In Water with Smile).Aplikované pohybové aktivity $v$ teorii a praxi, 2(1), 20-26.

Pacholík, V., Vlčková, I. \& Blahutková, M. (2009). Halliwickova metoda plavání. (Halliwick Method of Swimming). Brno: Masarykova Univerzita.

Russell, D. J., Rosenbaum, P. L., Avery, L. M. \& Lane, M. (2002). Gross Motor Function Measure (GMFM-66 and GMFM-88) User's Manual. London, United Kingdom:
Mac Keith Press.

Stan, A. E. (2012). The benefits of participation in aquatic activities for people with disabilities. Medicina Sportiva, 1, 1737-1742.

Šarinová, M. \& Čechovská, I. (2005) Plavecká poloha u dětí s diagnózou dětská mozková obrna:Role pohybových aktivit $v$ životě dètí a mládeže. (Swimming Position in Children with Cerebral Palsy: The Role of Physical Activities in Lives of Chldren).Praha: Falon.

Tirosh, R., Katz-Leurer, M. \& Getz, M., D. (2008). Halliwick-based aquatic assessments: reliability and validity, International Journal of Aquatic Research and Education, 2. 224-236.

Válková, H., (2010) Kudy na to?O motorické kompetenci a principech adaptace $v$ APA. (Where to go? About Motor Competencies and Principles of Adaptations in APA). Aplikované pohybové aktivity v teorii a praxi 1(2), 31- 39. 